\title{
KEEFEKTIFAN KALIMAT DALAM KARANGAN EKSPOSISI PESERTA DIDIK KELAS VIII-B SMP NEGERI 24 BANJARMASIN
}

\section{THE EFFECTIVENESS OF SENTENCES IN ESSAY EXPOSITION OF CLASS VIII-B STUDENTS AT SMP NEGERI 24 BANJARMASIN}

\author{
Aas Charniago; Noor Cahaya; Faradina \\ Program Studi Pendidikan Bahasa dan Sastra Indonesia \\ FKIP Universtas Lambung Mangkurat \\ charniago85@gmail.com
}

\begin{abstract}
Abstrak
Tujuan penelitian ini, yaitu mendeskripsikan keefektifan kalimat dalam karangan eksposisi peserta didik kelas VIII SMP Negeri 24 Banjarmasin. Metode penelitian yang digunakan, yaitu metode deskriptif kualitatif. Data penelitian, yaitu kalimat dalam karangan eksposisi. Instrumen penelitian menggunakan tabel analisis ciri kalimat efektif dengan bantuan peneliti. Hasil penelitian menunjukkan penggunaan kalimat efektif dan kalimat tidak efektif berdasarkan (1) kesepadanan struktur; (2) keparalelan bentuk; (3) ketegasan makna, yaitu peletakan frasa dan partikel; (4) kehematan kata, yaitu pengulangan subjek dihilangkan, menghindari kesinoniman, dan tidak menjamakkan frasa berbentuk jamak; (5) kecermatan dan kesantunan, yaitu pemilihan kata yang tepat dan tidak tepat; (6) kepaduan makna, yaitu keutuhan bentuk kata; dan (7) kelogisan makna, yaitu tidak ambigu.
\end{abstract}

Kata kunci: kalimat efektif, karangan eksposisi

\begin{abstract}
The purpose of this study is to describe the effectiveness of sentences in exposition essays students in class VIII-B SMP Negeri 24 Banjarmasin. This research method used is descriptive qualitative method. Research data that is the sentence in the essay exposition. The research instrument used the table of analysis of effective sentence characteristics with the help of researchers. The result showed the use of effective and ineffective sentences based on (1) structural equivalence; (2) the alignment of forms; (3) firmness of meaning, laying phrases and particles; (4) wor saving, repetition of the subject is eliminated, avoiding synonymy, and not pluralizing plural phrases; (5) meticulousness and politeness is the choice of the right and wrong words; (6) cohesiveness of meaning is the integrity of the form of meaning; and (7) logic of meaning is unambiguous.
\end{abstract}

Keywords: effective sentence, exposition essay

\section{Pendahuluan}

Permasalahan penelitian karya ilmiah dalam memahami sebuah tulisan tidak dapat diantisipasi. Masalah penelitian kalimat efektif dianggap sebagai permasalahan utama yang sulit diantisipasi. Kalimat efektif dapat menyampaikan informasi dengan mudah kepada pembaca. Kemudahan pembaca dapat diukur dari pendek dan panjang sebuah kalimat. Tulisan panjang belum tentu mudah dipahami pembaca, begitu pula sebaliknya.

Kesulitan peserta didik dalam kegiatan menulis disebabkan oleh minat masih 
kurang dan karangan yang ditulis tidak sesuai dengan keinginan peserta didik. Hal tersebut menjadi alasan peneliti memilih masalah ini karena peserta didik belum bisa mengembangkan ide secara logis dan tepat.

Alasan peneliti memilih karangan eksposisi karena berdasarkan pembelajaran yang harus dicapai di SMP atau MTs. Alasan mengambil data di kelas VIII-B karena kelas ini yang dianjurkan oleh guru untuk diteliti.

Alasan lain peneliti mengambil sumber data di SMP Negeri 24 Banjarmasin karena terakreditasi A. Sekolah tersebut belum pernah dilakukan penelitian kalimat efektif terhadap karangan eksposisi. Selain itu, sekolah tersebut merupakan sekolah unggulan dan sering memenangkan lomba akademik maupun non-akademik.

Peneliti menggunakan tujuan penelitian untuk memecahkan masalah secara menyeluruh. Tujuan penelitian ini, yaitu mendeskripsikan keefektifan kalimat dalam karangan eksposisi peserta didik kelas VIII SMPN 24 Banjarmasin

\section{Metode Penelitian}

\section{Jenis Penelitian}

Jenis dari penelitian ini menggunakan metode kualitatif bersifat deskriptif. Penelitian deskriptif bertujuan mengemukakan hasil data lapangan secara berurutan. Hasil data dideskripsikan dengan tujuan memperoleh pemahaman dengan tepat.

\section{Waktu dan Tempat Penelitian}

Waktu pelaksanaan Senin, 12 Oktober 2019. Penelitian dilaksanakan di SMPN 24 Banjarmasin Komplek Madani No. 5 RT. 31 Kelurahan Surgi Mufti, Kecamatan Banjarmasin Utara, Kalimantan Selatan, Kode Pos 70122. Penelitian dilakukan di kelas VIII-B karena sesuai dengan materi pada hari yang sudah dijadwalkan.

\section{Target atau Subjek Penelitian}

Subjek yang terdapat pada penelitian ini ialah karangan eksposisi. Jumlah data 34 karangan eksposisi yang ditulis peserta didik. Karangan eksposisi ditulis peserta didik menggunakan tema sama, yaitu olahraga untuk kesehatan tubuh. Hal ini didasarkan pada tugas yang diberikan guru dalam menulis karangan eksposisi.

\section{Prosedur}

Data, Instrumen, dan Teknik

\section{Pengumpulan Data}

Data yang terdapat pada penelitian ini ialah kalimat dalam karangan eksposisi.

\section{Instrumen Penilaian Karangan Eksposisi Peserta Didik Berdasarkan Ketepatan Kalimat}

Nilai $=\frac{\text { Jumlah Kalimat Efektif }}{\text { Jumlah Kalimat Karangan Eksposisi }}$ X 100 
Teknik pengumpulan data yang terdapat dalam penelitian ini ada tiga tahap, antara lain:

a. Observasi

Gunawan

$(2013: 143)$

mengemukakan observasi adalah metode dasar dan tua, karena keterlibatan kita dengan cara tertentu dalam proses mengamati. Peneliti mengamati guru mengajar di kelas VIIIB tanpa bantuan alat standar untuk keperluan tersebut.

b. Wawancara

Wawancara dilakukan di luar jam pelajaran pada 28 September 2019. Tujuan wawancara untuk mendapatkan informasi kesulitan peserta didik dalam menulis karangan eksposisi menggunakan kalimat efektif.

c. Dokumen

Dokumen pada penelitian ini, yaitu lembar kerja peserta didik berupa karangan eksposisi kelas VIII-B SMP Negeri 24 Banjarmasin.

\section{Teknik Analisis Data}

Akbar (2008:84) mengemukakan teknik analisis data, yaitu memperoleh tema, menafsirkan hal bermakna, dan menyampaikan kepada orang lain dengan jelas. Berikut teknik analisis yang digunakan, (1) pengkodean nama,
(2) data dikelompokkan dengan cermat,

(3) analisis data sesuai kategori kalimat efektif, dan (4) data disimpulkan dalam bentuk deskripsi.

Hasil Penelitian dan Pembahasan
Peneliti menganalisis data menggunakan tujuh ciri kalimat efektif. Ciri kalimat efektif tersebut berdasarkan teori dari Rahardi (2009:129). Berikut hasil dan pembahasan, antara lain:

\section{Kesepadanan Struktur}

Akhadiah (2008:116) memaparkan kesepadanan struktur ialah bentuk kalimat harus menciptakan keterpaduan arti yang merupakan ciri keutuhan kalimat.

Peserta didik RAS menggunakan frasa dengan sepadan pada K.5, P.2. Hal tersebut tidak menyalahi aturan ciri kesepadanan struktur.

Kalimat benar:

Olahraga juga dapat meningkatkan metabolisme tubuh.

Peneliti tidak hanya menemukan kalimat menggunakan ciri kesepadanan struktur dengan tepat, terdapat kalimat tidak menggunakan ciri kesepadanan struktur dengan tepat, antara lain:

\section{a.Kalimat mempunyai subjek dan predikat kalimat jelas}


Peserta didik DOS menggunakan kata keterangan aspek akan di depan subjek pada K.2, P.1.

Kalimat salah:

Olahraga memiliki banyak sekali.... Akan membuat....

Kata akan berfungsi memperjelas kalimat sebelumnya, kata akan dapat diletakkan sebelum predikat, bukan sebelum subjek kalimat. Oleh karena itu, kata akan diganti kata olahraga sebagai subjek agar kalimat menjadi sepadan.

Kalimat benar:

Olahraga membuat sehat dan menghindarkan kita dari penyakit.

\section{b.Konjungsi intrakalimat tidak}

digunakan pada kalimat tunggal

Peserta didik ACW menggunakan kata penghubung intrakalimat diletakkan setelah tanda titik terdapat pada K.2 dan K.3 paragraf keempat.

Kalimat salah:

Olahraga sangatlah penting untuk kesehatan manusia. Dengan berolahraga banyak manfat yang bisa di dapat . seperti terhindar dari penyakit.

Kalimat tersebut akan sepadan, jika sebelum kata dengan dan seperti tidak diberi tanda titik. Penggunaan kata penghubung intrakalimat dengan dapat diletakkan di tengah kalimat, sedangkan kata seperti dihilangkan agar menjadi kalimat efektif.
Kalimat benar:

Olahraga penting untuk kesehatan manusia, dengan berolahraga dapat menghindarkan tubuh dari penyakit.

\section{c. Kata yang tidak boleh di depan predikat}

Peserta didik YQ menggunakan kata yang di depan predikat pada K.4, P.2.

Kalimat salah:

...paparan sinar matahari yang

mengandung vitamin $\mathrm{D}$...

Kalimat tersebut akan sepadan, jika kata yang tidak diletakkan sebelum kata mengandung sebagai predikat. Penggunaan kata yang dapat dihilangkan agar menjadi kalimat efektif.

Kalimat benar:

...paparan sinar matahari mengandung vitamin D....

\section{Keparalelan Bentuk}

Widyamartaya

(2009:30) menyatakan keparalelan (kesejajaran) ialah unsur kalimat yang sama fungsinya dalam penggunaan bentuk gramatikal yang sama.

Peserta didik APS mengunakan ciri keparalelan bentuk pada K.1 dan K.2 paragraf kedua. Hal tersebut tidak menyalahi aturan ciri keparalelan bentuk. 
Kalimat benar:

Olahraga membuat.... karena dapat melepaskan....

Peneliti tidak hanya menemukan kalimat menggunakan ciri keparalelan bentuk dengan tepat, terdapat kalimat tidak menggunakan ciri keparalelan bentuk dengan benar, sebagai berikut:

\section{a. Kesejajaran bentuk}

Peserta didik ACW tidak menggunakan keparalelan bentuk pada K.1, P.3. Hal tersebut membuat kalimat tidak paralel.

Kalimat salah: ...beraktivitas atau berolahraga seperti lari, dan berenang akan mencegah kita dari penyakit jantung.

Kalimat tersebut menyalahi aturan kesejajaran bentuk, kata lari dan kata berenang. Bentuk kata tersebut harus diparalelkan agar menjadi kalimat efektif.

Kalimat benar:

...beraktivitas atau berolahraga, seperti berlari dan berenang akan mencegah kita dari penyakit jantung.

\section{b. Kesejajaran makna}

Peserta didik RFA tidak menggunakan keparalelan bentuk pada K.1, P.2. Hal tersebut membuat kalimat tidak paralel.

Kalimat salah:

...juga dapat merubah suasana hati menjadi tenang....
Kalimat tersebut menyalahi aturan kesejajaran makna, yakni kata merubah. Kata dasar ubah bukan rubah sejenis binatang. Bentuk kata tersebut harus diganti mengubah agar menjadi kalimat efektif.

Kalimat benar:

...juga dapat mengubah suasana hati menjadi tenang....

\section{c. Kesejajaran rincian pilihan}

Peserta didik FA tidak menggunakan keparalelan bentuk pada K.1, P.2. Hal tersebut membuat kalimat tidak paralel.

Kalimat salah: ...contohnya renang, lari lompat, back up, push up, shit up, bersepeda,....

Kalimat tersebut menyalahi aturan kesejajaran rincian pilihan, kata renang dan kata bersepeda. Urutan rincian tersebut harus diparalelkan berdasarkan pengunaan bahasa agar menjadi kalimat efektif.

Kalimat benar:

...contoh berenang,, berlari, berlompat, bersepeda, back up, push up, shit up,....

\section{Ketegasan Makna}

Rahardi (2009:56) berpendapat bahwa penegasan memberi tekanan suara pada suku kata atau kata.

Peserta didik AZ menggunakan penegasan frasa, tetapi tidak diletakkan di depan kalimat pada K.1, P.4. 
Pemindahan letak frasa berpengaruh terhadap penekanan kalimat.

Kalimat salah:

$\begin{array}{lcr}\text { Apabila tubuh } & \text { normal, } \\ \text { olahraga tentu } & \text { akan } \\ \text { menyehatkan tubuh. } & \end{array}$

Kalimat tersebut akan efektif dan penekanan kalimat jelas, jika frasa apabila tubuh normal tidak diletakkan di depan kalimat. Frasa olahraga menyehatkan tubuh merupakan frasa penekanan dan diletakkan di depan kalimat agar menjadi kalimat efektif.

Kalimat benar:

Olahraga menyehatkan tubuh, apabila dilakukan dengan kondisi tubuh normal.

\section{Kehematan Kata}

Rahardi (2009:105) menyatakan kehematan dengan membuang bagian yang memiliki makna sama.

Peserta didik RAC menggunakan kehematan kata, tidak menggunakan subjek ganda, penggunaan kata bersinonim, dan tidak menjamakkan kata berbentuk jamak pada K.5, P.2. Hal tersebut tidak menyalahi aturan kehematan kata, tidak menggunakan subjek ganda.

Kalimat benar:

Olahraga juga dapat meningkatkan metabolisme tubuh.

$$
\text { Peneliti tidak hanya }
$$

menemukan

kalimat menggunakan ciri kehematan kata dengan benar, terdapat kalimat tidak menggunakan ciri kehematan kata dengan benar, sebagai berikut:

\section{a. Penghilangan subjek ganda}

Peserta didik EF melakukan kesalahan kehematan kata pada K.1, P.1. Hal tersebut menyalahi aturan pengulangan subjek.

Kalimat salah:

...semakin kita banyak
olahraga maka kita kan
terhindar dari penyakit.

Subjek ganda kita merupakan pengulangan subjek dalam satu kalimat.

Kalimat benar:

...semakin kita banyak olahraga, akan terhindar dari penyakit.

\section{b. Penghindaran kesinoniman}

Peserta didik FA melakukan kesalahan kehematan kata pada K.2, P.5. Hal tersebut menyalahi aturan menggunakan kata bersinonim.

Kalimat salah:

...kita merasa letih atau

lelah....

Penggunaan kata letih dan lelah memiliki makna sama. Kalimat akan hemat, jika menggunakan kata letih atau kata lelah.

Kalimat benar:...kita merasa letih.... 


\section{c.Tidak menjamakkan frasa berbentuk jamak}

Peserta didik FA melakukan kesalahan kehematan kata pada K.1, P.1. Hal tersebut menyalahi aturan menjamakkan frasa berbentuk jamak.

Kalimat salah:

...olahraga berfungsi untuk

menjaga kesehatan tubuh kita.

Makna kata berfungsi dan makna kata untuk sama. Bentuk berfungsi untuk merupakan bentuk rancu dan mubazir. Cukup menggunakan kata berfungsi atau kata untuk agar menjadi kalimat efektif.

Kalimat benar:

...olahraga berfungsi menjaga

kesehatan tubuh kita.

\section{Kecermatan dan Kesantunan}

Rahardi (2009:176) berpendapat bahwa kesantunan berarti kata tidak memiliki makna yang dapat menyinggung pembaca.

Peserta didik AZ melakukan kesalahan kecermatan dan kesantunan pada K.2, P.2. Hal tersebut menyalahi aturan penggunaan diksi kurang tepat.

Kalimat salah:

...berjalan di halte bus, dll tentu....

Ungkapan dan lain-lain dalam kalimat tersebut tidak cermat. Ungkapan dan lain-lain tidak tepat karena ungkapan tersebut digunakan pada perincian beragam. Ungkapan dan lain-lain harus diubah menjadi ungkapan dan sebagainya. Ungkapan dan sebagainya digunakan pada perincian lebih lanjut yang bentuknya sejenis.

Kalimat benar:...berjalan di halte bus, dan sebagainya. Tentu....

\section{Kepaduan Makna}

Rahardi (2009:134) menyatakan padu adalah bersatu, artinya bentuk kebahasaan tidak terpecah-pecah. Makna kata dalam sebuah kalimat tidak tumpang tindih dengan kalimat selanjutnya.

Peserta didik FA melakukan kesalahan penggunaan ciri kepaduan makna kalimat pada K.2, P.1. Hal tersebut menyalahi aturan penggunaan kalimat bertele-tele.

Kalimat salah:

...manfaat dari kita berolahraga sangat banyak sekali, misalnya setelah kita berolahraga tubuh kita akan terasa segar dan bugar.

Kalimat tersebut bertele-tele karena menggunakan kalimat panjang, tetapi sulit dipahami pembaca. Kalimat akan padu jika menggunakan tanda baca tepat dan menghilangkan kata atau frasa yang tidak mempengaruhi makna kalimat. Kata atau frasa bercetak miring 
dapat dihilangkan atau diganti kata atau frasa baru.

Kalimat benar:

Olahraga berfungsi menjaga

kesehatan tubuh. Manfaat

olahraga, yaitu tubuh kita akan

terasa segar dan bugar.

\section{Kelogisan Makna}

Rahardi (2009:141) menyatakan kelogisan ialah gagasan kalimat dapat diterima daya pikir manusia.

Peserta didik FA melakukan kesalahan ciri kelogisan makna kalimat pada K.1, P.2. Hal tersebut menyalahi aturan ciri penggunaan kata tidak masuk akal.

Kalimat salah:

...renang,, lari lompat, back up, push up,....

Frasa bercetak miring tersebut tidak masuk akal. Kata lari lompat dapat membingungkan pembaca. Kalimat tersebut dapat diubah menggunakan kata lari atau lompat, bukan digabung lari lompat. Kata tersebut dapat diterima akal manusia jika ditambahkan tanda baca koma.

Kalimat benar: ...renang, lari, lompat, back up, push up,....

\section{Simpulan dan Saran}

\section{Simpulan}

Peserta didik kelas VIII-B SMP Negeri 24 Banjarmasin sudah berhasil menulis karangan eksposisi penggunaan kalimat dengan tepat. Selain itu, peneliti juga mendapatkan kesalahan penggunaan kalimat. Ketepatan terbanyak penggunaan ciri kalimat efektif, yaitu kepaduan makna. Kesalahan terbanyak penggunaan ciri kalimat efektif, yaitu kesepadanan struktur.

\section{Saran}

1. Peserta didik harus lebih giat berlatih menulis karangan eksposisi menggunakan kalimat efektif agar peserta didik mampu menghasilkan karangan dengan baik dan mudah dipahami.

2. Guru harus memberikan keterangan yang jelas sebelum mengajar materi menulis karangan eksposisi menggunakan kalimat efektif. Hal tersebut agar peserta didik lebih memahami penggunaan kalimat efektif dalam menulis karangan eksposisi.

3. Pembaca atau peneliti berperan aktif dalam mengembangkan penulisan karangan eksposisi menggunakan kalimat efektif.

4.Sekolah diharapkan mampu memberikan pelajaran tambahan atau kelas khusus untuk menulis menggunakan kalimat efektif. 


\section{Daftar Pustaka}

Akbar.2008. Metodologi Penelitian Sosial. Jakarta: BumiAksara.

Alkaf, Halid. 2009. Metode Penelitian Pendidikan. Tangerang: Islamic Research Publising.

Ariefin, Zainal. 2011. Model Penelitian dan Pengembangan. Bandung: Remaja Rosdakarya.

Bistok. 2009. Pedoman KaranganMengarang. Jakarta: Permendikbud.

Bungin, Burhan. 2010. Penelitian Kualitatif. Jakarta: Kencana.

Damayanti. 2014. Keefektifan Kalimat dalam

Karangan Eksposisi Siswa Kelas VII SMP Negeri 1 Grogol Kabupaten Kediri. Jurnal Pendidikan Bahasa dan Sastra Indonesia, Vol. 6 No. 2 (online). (http://karyailmiah.um.ac.id/index.php/sastraindonesia/article/view/36426), diakses pada tanggal 21 Februari 2019.

Gunawan, Imam. 2013. Analisis Keefektifan Surat Dinas Sekolah Menengah Pertama Negeri 6 Bintan. Skripsi. Tanjungpinang: UMRAH.

Hanafi, Abdul. 2011. Metode Penelitian Bahasa untuk Penelitian, Tesis, dan Disertasi. Jakarta: Diadit Media.
Akhadiah.2008. Pembinaan Kemampuan Menulis Bahasa Indonesia. Jakarta: Erlangga.

Parera. 2010. Belajar Mengemukakan Pendapat. Jakarta: Erlangga.

Rahardi, Kunjana. 2009. Penyuntingan Bahasa Indonesia untuk KarangMengarang. Jakarta:Erlangga.

Retnosari. 2015. Keefektifan Kalimat dalam Paragraf Eksposisi Peserta PLPG Universitas PGRI Adi Buana Surabaya. Jurnal Pendidikan Bahasa dan Sastra Indonesia, Vol. 5 No. 2 (online).

(http://ejournal.unp.ac.id/index.php/p bs/article/download/10010/7475), diakses pada tanggal 21 Februari 2019.

Semi. 2003. Menulis Efektif. Padang: Angkasa Jaya.

Widyamartaya. 2009. SeniMenggayakan Kalimat. Jogjakarta:Kanisius.

Wulandari, Suci. 2017. Keefektifan Kalimat dalam Karangan Eksposisi Siswa Kelas VII MTs Diniyah Pandai Sikek. Jurnal Pendidikan Bahasa dan Sastra Indonesia, Vol. 6 No. 2 diakses pada tanggal 21 Februari 2019. 
